\begin{tabular}{|l|l|l|}
\hline PUCRS & HUMANIDADES & $\begin{array}{l}\text { Educação por escrito, Porto Alegre, v. 11, n. 1, p. 1-7, jan.-jun. 2020 } \\
\text { e-ISSN: 2179-8435 }\end{array}$ \\
\hline de. http://dx.doi.org/10.15448/2179-8435.2020.1.32727 & \\
\hline
\end{tabular}

SEÇÃO: ARTIGOS

\title{
A efervescência do modo de pensar de Gilles Deleuze: conexões e proposições no cenário educacional
}

The effervescence of Gilles Deleuze's way of thinking: connections and propositions in education

Lilian dos Santos Silva ${ }^{1}$ orcid.org/0000-0002-0731-8770 li1207@gmail.com

Recebido em: 11 dez. 2018 Aprovado em: 8 jan. 2020. Publicado em: 27 jul. 2020.

\section{(c) (1)}

Artigo está licenciado sob forma de uma licença Creative Commons Atribuição 4.0 Internacional.
Resumo: No campo da educação, comumente iluminado pelo prisma da recognição e da representação, acionar o modo de pensamento de Gilles Deleuze e convocá-lo como companhia de pesquisa é soltar um comprimido efervescente em um copo d'água. O líquido muda, as moléculas se agitam; há movimento, barulho, ruido, excitação, entusiasmo, tumulto, transformação. Isso porque no contexto de ensino regido pela matriz platônica, as ideias do filósofo são uma perturbação. Uma euforia. Suas proposições desafiam o pensamento, tirando a segurança de processos, sem salvaguardar nada, e rompendo limites estabelecidos e consagrados. Nesse cenário, o objetivo deste artigo é apresentar alguns pontos de ebulição do modo de pensar de Gilles Deleuze, por meio de proposições do próprio filósofo. A partir delas, armam-se conexões com outros autores e com a literatura. Trata-se de Antonio Candido e Marcel Proust. Dessa forma, intenciona-se ensaiar possibilidades com a educação e, ao mesmo tempo, jogar luz na radicalidade que há na filosofia deleuziana.

Palavras-chave: Deleuze. Educação. Filosofia. Pensamento. Recognição.

Abstract: In the field of education, commonly illuminated by the prism of recognition and representation, to activate the mode of thought of Gilles Deleuze and summon him as a research company is to drop an effervescent pill into a glass of water. The liquid changes, the molecules agitate; there is movement, noise, noise, excitement, enthusiasm, tumult, transformation. This is because in the context of teaching, which is ruled by the Platonic matrix, the ideas of the philosopher are a disturbance. An euphoria. His propositions challenge the way of thinking, taking off the security of processes, without safeguarding nothing, and breaking established and consecrated boundaries. In this scenario, the purpose of this article is to present some boiling points of Gilles Deleuze's way of thinking, through propositions of the philosopher himself. From these, connections are armed with other authors and with the literature. These are Antonio Candido and Marcel Proust. In this way, the intention is to rehearse possibilities with education and, at the same time, to shed light on the radicality that exists in Deleuzian philosophy.

Keywords: Deleuze. Education. Philosophy. Thought. Recognition.

\section{Introdução: a questão da matriz educacional vigente}

A forma como a educação se estabelece por meio da recognição cerceia um modo de pensar mais amplo com aberturas, insights, epifanias e escapismos. Isso ocorre porque, na configuração educacional vigente, cuja matriz é acentuadamente platônica, o ato de pensar está ligado à representação, o que significa conhecer as coisas e o mundo a partir de uma imagem semelhante a de um objeto correspondente. Trata-se de uma organização relacional que opera em fechamentos, em um 
caráter reducionista: há o certo e o errado. Com essa dualidade, as respostas são taxativas, sem nuances e, de um modo mais amplo, estabelecese também a necessidade de uma adaptação a esse sistema em uma engrenagem de disciplinarização. Nele, impera o controle sobre muitos fatores desde o próprio comportamento até a avaliação. Com isso, como explica Melo (2010), se impõem modelos prontos e regras preestabelecidas, e os individuos são responsivos a conteúdos e a questões previamente definidos pelo sistema curricular. Essas tantas fechaduras para as quais é preciso se moldar, fazendose encaixar para o funcionamento do jogo, emperram ânimos, obstruindo aberturas e ideias.

A objetividade do veredito de alguma coisa ser isto ou aquilo rege um comando de controle também no sentido do ensino: controla-se como e quanto alguém aprende conforme a ideia de que só se aprende aquilo que é ensinado e, assim, assume-se que não se pode aprender sem que alguém ensine (GALLO, 2017). Por ser hermético e estanque, esse sistema tem a ordem como lógica e não há aí exatamente um problema para a educação. Ela pode seguir dessa forma, contudo há de se questionar por que deve ser assim na medida em que esse modo de operar não estimula o pensamento ao próprio pensar.

Silvio Gallo (2017) propõe que as perspectivas deleuzianas instigam, pois vão de encontro ao pensamento com objetivo utilitário e, à vista disso, pode-se pensar a educação mirando um ato de criação.

Pensamos, quando nos encontramos com um problema, com algo que nos força a pensar. E aprendemos quando pensamos. O aprender é, pois, um acontecimento da ordem do problemático. E é essa noção de problema que faz Deleuze defender a noção de um aprender que não é recognição, mas criação de algo novo, um acontecimento singular no pensamento (GALLO, 2017, p. 107, grifo nosso).

Eis uma possibilidade fora da caixa da representação, do mesmo, do já conhecido e da dualidade. No campo da educação, comumente iluminado pelo prisma da recognição, acionar o modo de pensamento de Deleuze e convocá- lo como companhia de pesquisa é soltar um comprimido efervescente em um copo d'água. Há movimento, barulho, ruido, excitação, entusiasmo, tumulto, transformação. Nesse contexto de ensino regido pela matriz platônica, acionar as ideias do filósofo é uma perturbação. Suas proposições desafiam o pensamento, tirando a segurança de processos, sem salvaguardar nada, e rompendo limites já estabelecidos e consagrados.

\section{$1 \mathrm{~A}$ árvore verdeja, verdejar, impermanência}

Na obra Lógica do sentido, há uma proposição bastante curta de efeito provocativo e intrigante: "a árvore verdeja" (DELEUZE, 2000, p. 22). Contemporiza-se que não é a árvore em si mesma que sofre e transborda esse processo. Entretanto, o verdejar é algo que não acontece fora dela, sem ela, pois depende de uma condição de vida da árvore. Diante do calor que essas palavras deleuzianas contêm - emanando vigor, força expansiva, mobilidade vital, febre interna, sinergia; em uma palavra, força - não se pode passar impune a elas.

"A árvore verdeja." O verdor, a verdura, paisagens do planeta. O verde-montanha no alto, o verdebandeira no mastro, o verde-água ao rés do chão, o verde-mar em um platô embrulhando a terra, o verde-esmeralda escondido e o auriverde no encontro com o ouro nas entranhas da mina. $O$ verde-garrafa, que guarda em si um conteúdo que fora, mergulhará corpos adentro. Morrer, tornarse verde, ornar-se de verde, verdecer, verdejar. O frescor, a calma da mata e, ao mesmo tempo, sua energia. Correndo devagar pelos troncos, as seivas fervem de dentro para fora. A luz da fotossintese eclode verde nas folhas. Uma explosão de todas as cores perpassadas pelo verde. O verde que é ele mesmo sua transcendência na imanência, e sabe da impermanência, sabe que sempre alguma coisa acontece. Parafraseando Guimarães Rosa, "Tudo, aliás, é a ponta de um mistério. Inclusive, os fatos. Ou a ausência deles. Duvida? Quando nada acontece, há um milagre que não estamos vendo" (1988, p. 65, grifo nosso). O verde sabe disso. O milagre também é verde. $E$ por que verde e não azul? O verde é azul também. Guarda o azul em si. Aos olhos de alguns, trata-se do próprio azul. 
Na ocasião em que foi convidado pelo Movimento Sem Terra (MST) para inaugurar uma biblioteca², o crítico literário Antonio Candido proferiu um discurso cujo trecho, a seguir, interessa a essa discussão.

Acho que uma das coisas mais sinistras da história da civilização ocidental é o famoso dito atribuido a Benjamim Franklin, "tempo é dinheiro". Isso é uma monstruosidade. Tempo não é dinheiro. Tempo é o tecido da nossa vida, é esse minuto que está passando. Daqui a 10 minutos eu estou mais velho, daqui a 20 minutos eu estou mais próximo da morte. Portanto, eu tenho direito a esse tempo. Esse tempo pertence a meus afetos. É para amar a mulher que escolhi, para ser amado por ela. Para conviver com meus amigos, para ler Machado de Assis. Isso é o tempo. Ejustamente a luta pela instrução do trabalhador é a luta pela conquista do tempo como universo de realização própria. A luta pela justiça social começa por uma reivindicação do tempo: "eu quero aproveitar o meu tempo de forma que eu me humanize". As bibliotecas, os livros, são uma grande necessidade de nossa vida humanizada (CANDIDO, 2006, grifo nosso).

Entremeia-se a fala de Antonio Candido com o esverdear de Deleuze pela impermanência. Tanto o tempo quanto o processo da árvore são algo que não se pode conter, são afetos em laboração. A instabilidade, a fragilidade e a sutileza da vida podem parecer distantes quando se está em uma lógica produtiva e incessante, seguindo a máxima atribuida a Benjamim Franklin. No entanto, a proximidade com a impermanência é plena, o que fica claro observando-se um movimento oposto.

O alvorecer não se pode cessar. O raiar do dia com o despontar do sol, seja com nuvens, seja em um céu aberto ou encoberto, impreterivelmente, se dá. Toda a alimentação do planeta com essa energia diária, da mesma forma, acontece. O mar aquece, esfria. As pedras aquecem, esfriam. Nosso corpo nasce, morre e renasce com suas incontáveis células que se multiplicam, se alimentam, geram e descansam. O pôr do sol e sua luz difusa - nesses instantes que marcam a transição entre o que é dia e noite e que captam a atenção ao insinuar e sinalizar essa mudança - igualmente seguem sem cessar. Nesse interim, somos efêmeros, temporários. Vivemos na impermanência.

A ideia de que o tempo dos afetos pode ser tomado para "amar a mulher que escolhi, para ser amado por ela" leva ao encontro de uma experiência acionada pela literatura de Em busca do tempo perdido (2006), de Marcel Proust, romance sobre o qual Deleuze se debruçou na obra Proust e os Signos (1987).

\begin{abstract}
De todos os modos de produção do amor, de todos os agentes de disseminação do mal sagrado, um dos mais eficazes é esse grande torvelinho de agitação que às vezes sopra sobre nós. Então a sorte está lançada e a criatura com quem nesse momento nos comprazemos será a criatura amada. Nem mesmo é necessário que até então nos tenha agradado mais que as outras, ou tanto como as outras. O que era preciso é que nossa inclinação por ela se tornasse exclusiva. E essa condição se realiza quando - no instante em que ela nos faltou - sentimos em nós não o desejo de buscar os prazeres que seu convivio nos proporciona, mas uma necessidade angustiosa, que tem por objetivo essa mesma criatura, uma necessidade absurda, que as leis deste mundo tornam impossivel de satisfazer e dificil de curar - a necessidade insensata e dolorosa de possuí-la (PROUST, 2006, p. 287).
\end{abstract}

Assim como Candido, Proust trata do encontro amoroso. Aborda um modo de sentir que, na maioria das vezes, torna-se difícil de explicar e articular com palavras. Ao se buscar empreender uma tentativa como essa, tem-se a ação de mover o sentir a uma forma outra, sendo que essa parece estar coagida a um limite. Com isso, Proust discorre sobre um assunto carregado de complexidade e de afecções. Ora, que poder é esse do romancista que, em sua literatura, instiga a pensar sobre o que mal se consegue falar ou explicar? Eis o choque. A habilidade de abordar essa situação deflagra um espantoso e inesperado efeito.

Pelas experiências de afetação aqui relatadas, os trechos de Candido e Proust e as palavras verdes de Deleuze literalmente fazem a vida parar, demandam uma pausa sem a qual não se pode seguir. Essa ideia está presente no que Deleuze apresenta como signo $^{3}$ na obra já mencionada

\footnotetext{
A Biblioteca Confraria dos Parceiros de Guararema integra o Centro de educação superior do MST, a Escola Nacional Florestan Fernandes, em Guararema, São Paulo. A inauguração ocorreu no dia 5 de agosto de 2006.

3 Vale sublinhar que a concepção deleuziana de signo é uma proposta específica, que não se vincula à definição estruturalista nem àquela relacionada à semiótica.
} 
Proust e os Signos (1987). Nela, o filósofo afirma que nunca se sabe ao certo como uma pessoa aprende. No entanto, independentemente da forma como aprenda, esse processo se dá sempre por intermédio de signos (DELEUZE, 1987). Ou seja, esse aprender está ligado a uma afetação, conectando-se a algo que é sensivel. Como argumento a esse raciocínio, Deleuze valese de uma citação do próprio romance.

Porque as verdades, direta e claramente, apreendidas pela inteligência no mundo da plena luz são de qualquer modo mais superficiais do que as que a vida nos comunica à nossa revelia, numa impressão física, já que entrou pelos sentidos, mas da qual podemos extrair o espirito (PROUST apud DELEUZE, 1987, p. 95, grifo nosso).

Segundo essa prescrição de Proust, nas palavras de Deleuze, "o que nos força a pensar é o signo. O signo é o objeto de um encontro; mas é precisamente a contingência do encontro que garante a necessidade daquilo que ele faz pensar" (1987, p. 96). No que se refere à afetação, "é preciso que o efeito violento de um signo seja sentido e que o pensamento seja como que forçado a procurar o sentido do signo" (DELEUZE, 1987, p. 23). À vista disso, o signo não tem representações prévias nem conteúdos de significação explicita, ele se dá em um encontro fortuito e inevitável. Assim, ao forjar esse encontro, o signo implica uma busca capaz de engendrar o ato de pensar no próprio pensamento.

\section{Encontros, conexões, o sensível e o imponderável "e" surfar na dobra da onda}

Desponta na fala de Deleuze sobre o signo a relevância dos encontros e, nesse sentido, destacam-se os acionamentos que o filósofo realizou ao longo de sua obra com variados artistas e autores. Aliás, segundo François Zourabichvili (2016), Deleuze sempre comentou outros autores, afirmando um pensamento próprio e original. Tomar essas ideias como disparadores possibilitou a ele desenvolver seus problemas e sua filosofia.

Integra o pensamento de Deleuze e Guattari a ideia de que não se faz nada sozinho. Eles defendem não a existência de um "eu" que pensa, isto é, não interessa o sujeito, mas a rede. Assim, o sentido não está no emissor nem nas coisas, é a rede de conexões que vai produzir sentidos.

Deleuze mostra, ao contrário, que o ato de pensar põe necessariamente em crise a subjetividade, e que a necessidade, longe de atender aos votos de um sujeito pensante já instituido, só é conquistada quando o pensamento está fora de si mesmo, pensamento que só é absolutamente potente na ponta extrema da sua impotência (ZOURABICHVILI, 2016, p. 47).

Com essa afirmação de Zourabichvili, enfatiza-se que, para Deleuze, o pensamento pode se realizar nas conexões com pessoas, objetos ou coisas. Ao filósofo interessava, portanto, os encontros e, a partir deles, seus efeitos. A ideia consistia em operar conexões em encadeamentos e atravessamentos múltiplos, o que remete à utilização do "e". Com isso, Deleuze defendia que importava a transformação do "é" em "e", "não no sentido de uma relação particular e puramente conjuntiva, mas no sentido de toda uma série de relações. O 'e' é atribuido à possibilidade de criação, à gagueira criadora, à multiplicidade" (DOSSE, 2010, p. 18). Tal proposta reafirma que o modo deleuziano de pensar desliza de uma ideia a outra e, seguindo esse rastro, podese perceber uma movência, lançando-se mão, para isso, de tirar ideias para dançar. Do mesmo modo, eis a efervescência do comprimido no copo d'água. Nela, o início de uma reação aciona "e" dispara o efeito em cascata, como peças de dominó que, enfileiradas, caem sucessivamente após um primeiro disparo.

Deleuze trata dos encontros na entrevista $O$ abecedário de Deleuze (1997) que concedeu a Claire Parnet. Na ocasião, ele afirma que quando vai a uma mostra artística ou ao cinema, não está certo se vai ter um encontro, mas parte à espreita. Se houver matéria para encontro, o que pode ser um quadro, um filme, então ele diz que é formidável. Observa-se, portanto, que a saída a uma mostra artística ou ao cinema não é condição do encontro que possui também um tom de mistério, pois estão incluidos o imponderável, o acaso, os sentidos, as afetações e os afetos.

Nessa perspectiva das conexões e das trocas, na mesma entrevista, Deleuze relata duas 
experiências que o marcaram. Ele acabara de lançar o livro A dobra: Leibniz e o Barroco (1991), no qual aborda uma noção que julga importante nesse filósofo, mas que considerava mais relevante ainda para si mesmo. Trata-se da própria dobra.

Considero que fiz um livro de filosofia sobre essa noção, um pouco estranha, de dobra. O que me acontece depois? Recebo cartas, como sempre, há cartas insignificantes, mesmo se são encantadoras e calorosas, e me toquem muito. São cartas que me dizem, muito bem... são cartas de intelectuais que gostaram ou não do livro. E então recebo duas cartas, dois tipos de carta, em que esfrego os olhos... Há cartas de pessoas que dizem: "mas sua história de dobra, somos nós". E percebo que são pessoas que fazem parte de uma associação que agrupa 400 pessoas na França, hoje, e deve crescer. É a associação de dobradores de papéis, eles têm uma revista, me enviam a revista e dizem: "concordamos totalmente, o que você faz é o que fazemos". Digo para mim: isso eu ganhei. Recebo outra carta, e falam da mesma maneira e dizem: "a dobra somos nós". É uma maravilha. [...] Tive esta experiência, os dobradores de papéis chegam e dizem: a dobra somos nós (DELEUZE, 2018, p. 12).

Percebe-se a satisfação do filósofo com o encontro que o livro de questões filosóficas, a partir de Leibniz, lhe proporcionou, sendo mais interessante ainda o fato desses interlocutores, além de concordarem com os escritos, afirmarem que são a própria dobra. O autor deu a eles algo a pensar sobre sua atividade, mas não foram só os dobradores de papel que enviaram cartas.

Os outros, que me enviaram o mesmo tipo de carta, é incrivel, foram os surfistas. À primeira vista não há relação alguma com os dobradores de papéis. Os surfistas dizem: "concordamos totalmente, pois, o que fazemos? Estamos sempre nos insinuando nas dobras da natureza. Para nós, a natureza é um conjunto de dobras móveis. Nós nos insinuamos na dobra da onda, habitar a dobra da onda é a nossa tarefa". Habitar a dobra da onda e, com efeito, eles falam disso de modo admirável. Eles pensam, não se contentam em surfar, eles pensam o que fazem (DELEUZE, 2018, p. 12-13).

Assim, do mesmo modo anterior, outro grupo de pessoas chamou a atenção do filósofo por articular uma armação a partir de uma ideia, revelando, com isso, o ato de pensar em jogo. A essa altura, na entrevista, Claire Parnet pergunta se esses são encontros.
São encontros. [...] Não preciso vê-los, mas tive um encontro com o surfe, com os dobradores de papéis, literalmente, sai da filosofia pela filosofia, é isso um encontro. Acho que os encontros... quando vou ver uma exposição, estou à espreita, em busca de um quadro que me toque, de um quadro que me comova, quando vou ao cinema, [...] [a] uma exposição de pintura, ou [a]o cinema... Sempre tenho a impressão que posso ter o encontro com uma ideia (DELEUZE, 2018, p. 13).

Dos encontros com ideias passa-se aos encontros com pessoas. Na mesma entrevista, Claire Parnet questiona o entrevistado sobre os amigos, afirmando, de largada, que eles são muito importantes para o filósofo. E pergunta se é correta a impressão de a fidelidade estar obrigatoriamente ligada à amizade ou vice-versa. Deleuze afirma que não há fidelidade, trata-se de uma questão de conveniência.

É outra coisa. A amizade. Por que se é amigo de alguém? Para mim, é uma questão de percepção. É o fato de... Não o fato de ter ideias em comum. O que quer dizer "ter coisas em comum com alguém"? Vou dizer banalidades, mas é se entender sem precisar explicar. Não é a partir de ideias em comum, mas de uma linguagem em comum, ou de uma pré-linguagem em comum. Há pessoas sobre as quais posso afirmar que não entendo nada do que dizem, mesmo coisas simples como: "passe-me o sal". Não consigo entender. E há pessoas que me falam de um assunto totalmente abstrato, sobre o qual posso não concordar, mas entendo tudo o que dizem. Quer dizer que tenho algo a dizer-lhes e elas a mim. E não é pela comunhão de ideias. Há um mistério aí. Há uma base indeterminada... É verdade que há um grande mistério no fato de se ter algo a dizer a alguém, de se entender mesmo sem comunhão de ideias, sem que se precise estar sempre voltando ao assunto. Tenho uma hipótese: cada um de nós está apto a entender determinado tipo de charme. Ninguém consegue entender todos os tipos ao mesmo tempo. Há uma percepção do charme. [...] [U]m gesto, um pensamento de alguém, mesmo antes que este seja significante, um pudor de alguém são fontes de charme que têm tanto a ver com a vida, que vão até as raizes vitais que é assim que se torna amigo de alguém. [...] Há de fato uma questão de percepção. Perceber algo que the convém, que ensina, que abre e revela alguma coisa (DELEUZE, 2018, p. 32-33, grifo nosso).

Mais uma vez surge na proposta de Deleuze a importância do encontro pelo sentido, pela afetação e aqui, especificamente, tendo em vista o mistério que há na afinidade entre pessoas, afinal, trata-se de algo que é para ser sentido. Ao abordar esse contato 
tão íntimo nesses termos, ele mostra a magia que existe nessa forma de estima e propõe que ela envolve uma percepção de charme. Nesse sentido, Deleuze afirma que "alguém emite signos e a gente os recebe ou não. Acho que todas as amizades têm esta base: ser sensivel aos signos emitidos por alguém" (DELEUZE, 1997, p. 33). Acredita-se que experienciar relações de amizade pode abranger essa sutil tessitura sensivel, o que faz dessa ideia deleuziana um disparador para se pensar também nos efeitos desses relacionamentos nos próprios modos de existência.

Tendo em vista a produção em conjunto de Deleuze e Guattari, sublinha-se que os autores empreenderam um modo de pensamento que chama atenção por uma escrita em dupla autoria. Em Carta a Uno: como trabalhamos a dois (DELEUZE, 2016), uma correspondência de Deleuze endereçada a Kuniichi Uno, o filósofo explica como realizava seu trabalho com Félix Guattari. "Nossas conversas comportavam elipses cada vez mais numerosas e podiamos estabelecer ressonâncias de toda sorte, não mais entre nós, mas entre os domínios que atravessávamos" (DELEUZE, 2016, p. 251, grifo nosso). Nota-se presente a produção do pensamento pela abrangência de atravessamentos e, no mais, observa-se que a amizade viabilizou uma zona de confiança para que se pudesse ousar e receber a fricção, o delírio, os silêncios e as pausas do outro. Isso incluiu o efeito da produção na rede e, ao mesmo tempo, a possibilidade de o pensamento fluir. Destaca-se ainda que, no processo de escrita dos autores, a linguagem existe como ato e não como representação. Ela não era anterior, mas se fazia à medida que se fazia o pensamento.

\section{Considerações finais}

Essas proposições incandescentes convergem para o principal alvo ao qual Deleuze se atém. "O exercício do pensamento e a possibilidade de novas formas de expressão do pensar percorrem toda a sua obra" (VASCONCELLOS, 2005, p. 1218). Com isso, a efervescência mencionada pode instaurar o ato e o exercício do pensamento pelo estímulo e a inquietação provocativos que possui.
Tal movimento pode possibilitar conexões e, desse modo, novas formas de expressão. Ressalta-se, no entanto, que isso só se dá a partir de uma maneira muito própria por meio da qual o filósofo concebe o pensar. Tendo em vista essa contingência, para ele, pensar é da ordem do imprevisivel, em uma abertura à criação e à produção da diferença que não obedece a uma teleologia. Trata-se de uma experiência sem qualquer salvaguarda.

Acrescenta-se, ainda, que a discussão aqui empreendida se dá no âmbito da educação, contudo destaca-se que essas perspectivas deleuzianas vão além. Elas não se restringem somente a possibilidades de pensar relacionadas à sala de aula. Pode-se tomá-las para um arremesso de vulto maior: um modo de viver, de produzir com sensações, de deslocar-se das concepções convencionais de tempo e de espaço. Eis, portanto, o gesto de dispor o próprio corpo e a vida nos atravessamentos desses fluxos, compondo modos de existência, ou seja, modos de viver diferentes, em um ato, sobretudo, forte e afirmativo de criação.

Assim, este artigo procurou apresentar alguns pontos de ebulição do modo de pensar de Gilles Deleuze, por meio de proposições do filósofo. A partir delas, armaram-se conexões com uma fala de Antonio Candido e com a literatura de Marcel Proust, unindo-as pelo viés do sensivel, dos sentidos e da possibilidade de ser afetado. A questão dos encontros também foi abordada alinhavando a importância das trocas e da interlocução no estímulo ao pensar. Desse modo, a efervescência deleuziana aqui destacada indica uma vereda para se pensar nos afetos. Eis uma tentativa e um ensaio - mínimos que sejam sobre a possibilidade do que poderia vir a ser a intensidade de verdejar. O que se acredita se tratar do "grande torvelinho de agitação que às vezes sopra sobre nós" (PROUST, 2006, p. 287).

Ao evidenciar, como propõe o filósofo, o que dá a pensar e os efeitos do próprio ato de pensar, buscouse indicar uma trama que refrata a recognição e assim intentou-se desdobrar uma perspectiva para além da redução do pensamento à simples forma da representação. Ao procurar possibilidades a partir de disparadores da filosofia deleuziana, pode-se 
vislumbrar que essa articulação permite jogar luz na radicalidade do modo de pensamento do filósofo, pois ele abre caminhos para se pensara educação de outra forma. Nesse sentido, acredita-se que pesquisar essa perspectiva é algo necessário e caro à educação ao empreender um pensamento que não segue na busca pela semelhança ou por um modelo.

\section{Referências}

CANDIDO, Antonio. Antonio Candido inaugura biblioteca do MST e fala da força da instrução. Portal Carta Maior, Matéria de Verena Glass, de 08/08/2006. Disponivel em: https://www.cartamaior.com.br/?/ Editoria/Movimentos-Sociais/Antonio-Candido-inaugura-biblioteca-do-MST-e-fala-da-forca-da-instrucao/2/11075. Acesso em: 10 jul. 2018.

DELEUZE, Gilles. Proust e os signos. 2. ed. trad. Antonio Piquet e Roberto Machado. Rio de Janeiro: Forense Universitária, 1987 [1964].

DELEUZE, Gilles. A dobra: Leibniz e o Barroco. Tradução de Luiz Orlandi. Campinas, São Paulo: Papirus, 1991.

DELEUZE, Gilles. O abecedário de Gilles Deleuze. Entrevista com Gilles Deleuze. Editoração: Brasil, Ministério da Educação, TV Escola, 2001. Paris: Éditions Montparnasse, 1997, VHS, 459 min. Texto disponivel em http://stoa.usp.br/prodsubjeduc/ files/262/1015/Abecedario+G.+Deleuze.pdf. Acesso em: 13 abr. 2018

DELEUZE, Gilles. Lógica do sentido. Tradução de Luiz Roberto Salinas Fortes. São Paulo: Perspectiva, 2000.

DELEUZE, Gilles. Carta a Uno: como trabalhamos a dois. In: DELEUZE, Gilles. Dois Regimes de loucos. São Paulo: Editora 34, 2016. p. 249-251.

GALLO, Silvio. O aprender em múltiplas dimensões. Revista do Programa de Pós-graduação em educação matemática da Universidade Federal de Mato Grosso do Sul (UFMS), v. 10, n. 22, 2017. Disponivel em: http://Www.seer.ufms.br/index.php/pedmat/ article/view/3491 Acesso em: 30 maio 2018.

MELO, Danilo Augusto Santos. Resistência e criação nas práticas de ensino e aprendizagem, por uma educação aberta. Childhood \& Philosophy, Rio de Janeiro, v. 6, n. 12, p. 229-254, jul./dic. 2010. Disponivel em: https://www.redalyc.org/pdf/5120/512051605003. pdf. Acesso em: 30 maio 2018

PROUST, Marcel. No Caminho de Swann. Trad.: Mario Quintana. 3. ed. São Paulo: Ed. Globo, 2006. (Em Busca do Tempo Perdido, v. 1).

ROSA, Guimarães. O Espelho. In: ROSA, Guimarães. Primeiras Estórias. Rio de Janeiro: Nova Fronteira, 1988.
Zourabichvili, François. Deleuze: uma filosofia do acontecimento. São Paulo: Editora 34, 2016.

\section{Lilian dos Santos Silva}

Doutoranda em Educação pela Faculdade de Educação da Universidade de São Paulo (USP, São Paulo, SP, Brasil).

\section{Endereço para correspondência}

Lilian dos Santos Silva

Universidade de São Paulo

Departamento de Filosofia da Educação e Ciências da Educação

Av. da Universidade, 308, bloco A, $1^{\circ}$ andar

Cidade Universitária, 05508-040

São Paulo, SP, Brasil 